\title{
High-performance supercapacitors and batteries derived from activated banana-peel with porous structures
}

\author{
Yunya Zhang, Zan Gao, Ningning Song, Xiaodong Li* \\ Department of Mechanical and Aerospace Engineering, University of Virginia, 122 Engineer's Way, Charlottesville, VA 22904-4746, USA
}

\section{A R T I C L E I N F O}

\section{Article history:}

Received 1 November 2016

Received in revised form 15 November 2016

Accepted 17 November 2016

Available online xxx

\section{Keywords:}

banana peel

supercapacitor

lithium-sulfur battery

graphene

porous structure

\begin{abstract}
A B S T R A C T
Carbonaceous materials derived from non-renewable and non-sustainable graphite and fossil fuels have been widely used in building supercapacitor and battery electrodes but the mining and fabrication processes are often hazardous and contaminative. Therefore, to derive activated carbon from renewable bio-mass materials is environmentally and socially significant. Here a unique and innovative solution is proposed to produce supercapacitors and batteries from banana peels. Banana peel, which is one of the most abundant and accessible bio-wastes, naturally processes hierarchically porous structure, making activated banana peel (ABP) an ideal backbone for loading electroactive nanomaterials. The ABP derived asymmetric supercapacitors exhibited superior rate capacity and cyclic ability, as well as a synergetic enhancement of energy density and power density because the interconnected porous structure stimulated the formation of urchin-like $\mathrm{NiCO}_{2} \mathrm{O}_{4}$ particles, prevented the aggregation of $\mathrm{NiCo}_{2} \mathrm{O}_{4}$ nanowires, and enhanced the electrolyte accessibility. Orderly arranged nanopores with unique $\mathrm{Ni} /$ graphene core/shell nanoparticles were created by annealing the $\mathrm{Ni}\left(\mathrm{NO}_{3}\right)_{2}$ solution-treated ABP. The lithium-sulfur (Li-S) batteries built by the $\mathrm{ABP} / \mathrm{Ni} /$ graphene hybrid achieved exceptionally high electrochemical properties in terms of specific capacitance (1260.3 $\mathrm{mAh} \mathrm{g}^{-1}$ at $0.2 \mathrm{C}$ ), rate capability, and cycling robustness.
\end{abstract}

(c) 2016 Elsevier Ltd. All rights reserved.

\section{Introduction}

The escalation of global energy consumption and the depletion of fossil fuels, along with the parasitic climate change and air pollution, necessitate further exploitation of clean and sustainable energy sources, which require stable energy storage systems with high capacity. Furthermore, the recent surge of advanced electronic devices and electric vehicles imposes an urgent need for the development of more efficient electrical energy storage applications with superior performance. Batteries and supercapacitors, which can directly convert electrical energy into chemical energy, have been proven to be the most effective means for practical energy storage applications, and have revolutionized all aspects of modern society [1]. As the most widely used energy storage devices, batteries and supercapacitors display different advantages and disadvantages [2,3]. Batteries usually possess higher energy density while having lower power density, which makes them more suitable for large scale energy storage. Supercapacitors, on the other hand, are more promising for short-term

\footnotetext{
* Corresponding author.

E-mail address: xl3p@virginia.edu (X. Li).
}

energy storage or burst-mode power delivery, such as the regeneration of braking and the starting/climbing of cars, due to their high power density, fast charge/discharge rate, and longlasting cycle life.

Electrode materials play an important role in determining the electrochemical performance of both supercapacitors and batteries. To date, various electrode materials including carbon materials, transition-metal oxides and hydroxides, and conductive polymers have been explored for high performance energy storage devices [4-6]. Carbonaceous materials such as activated carbon, graphite, graphene, and carbon nanotubes have been extensively applied to energy storage systems because of their remarkable chemical stability, excellent mechanical robustness, high electronic conductivity, and outstanding electrolyte ion accessibility [7]. Specifically, porous carbon materials have been proven to be able to shorten ion diffusion path and buffer charge/discharge volume charge [8,9], thereby jointly facilitating the electrochemical reactions of supercapacitors and batteries. Besides performance considerations, due to the economic and environmental issues in practical applications, electrode materials also need to be low-cost and environmentally benign $[7,10]$. Unfortunately, the most popular carbon sources for electrodes currently are graphite and fossil fuels

Please cite this article in press as: Y. Zhang, et al., High-performance supercapacitors and batteries derived from activated banana-peel with porous structures, Electrochim. Acta (2016), http://dx.doi.org/10.1016/j.electacta.2016.11.099 
and the mining and fabrication processes of which are often hazardous and contaminative. Can we easily produce cheap and eco-friendly electrode materials with superior electrochemical properties? Encouragingly, as one of the most popular fruits, the banana says yes. Scientists and engineers are attempting to derive activated carbon from various bio-mass materials, but none of them are as abundant and accessible as banana peels. According to statistics, world banana production in 2011 was 145.4 million tons [11], while $9 \%$ of this banana production was abandoned due to surplus or being damaged during packing or shipping. Meanwhile, 26.5 million tons of banana peels were inedible for people and most livestock, and they were disposed of in landfills or by incineration at extra cost (Fig. 1a). Some efforts have been made to recycle bananas such as using bananas to produce methanol [12] and purify water $[13,14]$, but it is still necessary to find a larger industry to further promote the recycling of banana peels. Currently, activated carbon derived from bananas has displayed promising electrochemical properties for supercapacitors and battery applications [15-19]. Considering the massive output of battery products, to use banana peels-derived activated carbon in battery industry is a win-win strategy. However, these preliminary studies on activated banana-based carbon often involved complex physical and chemical synthesis procedures, inevitably increasing cost and environmental risks. More importantly, the porous nature of banana peels and their potential as free-standing electrodes and active materials carriers were largely overlooked.

Compositing carbonaceous materials with metal oxides to build high performance supercapacitors has been proven to be promising (a)

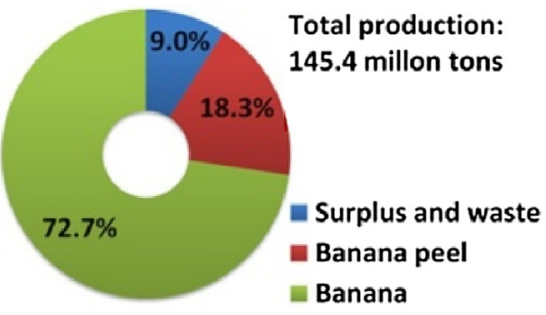

(d)

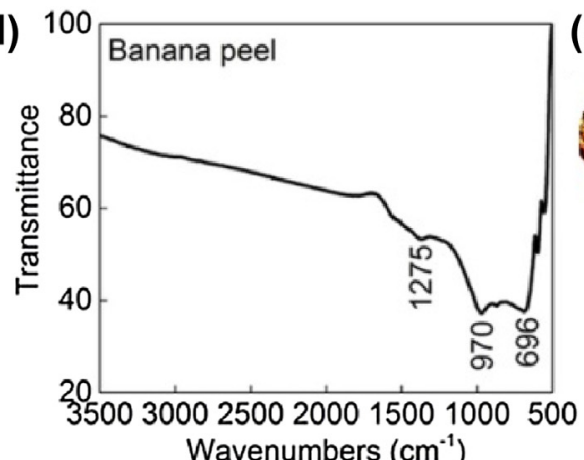

(b)

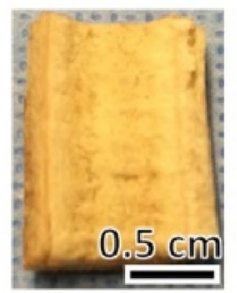

(c)

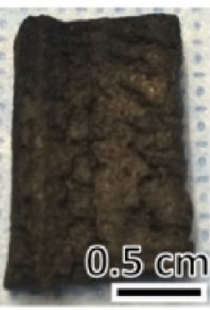

(f)
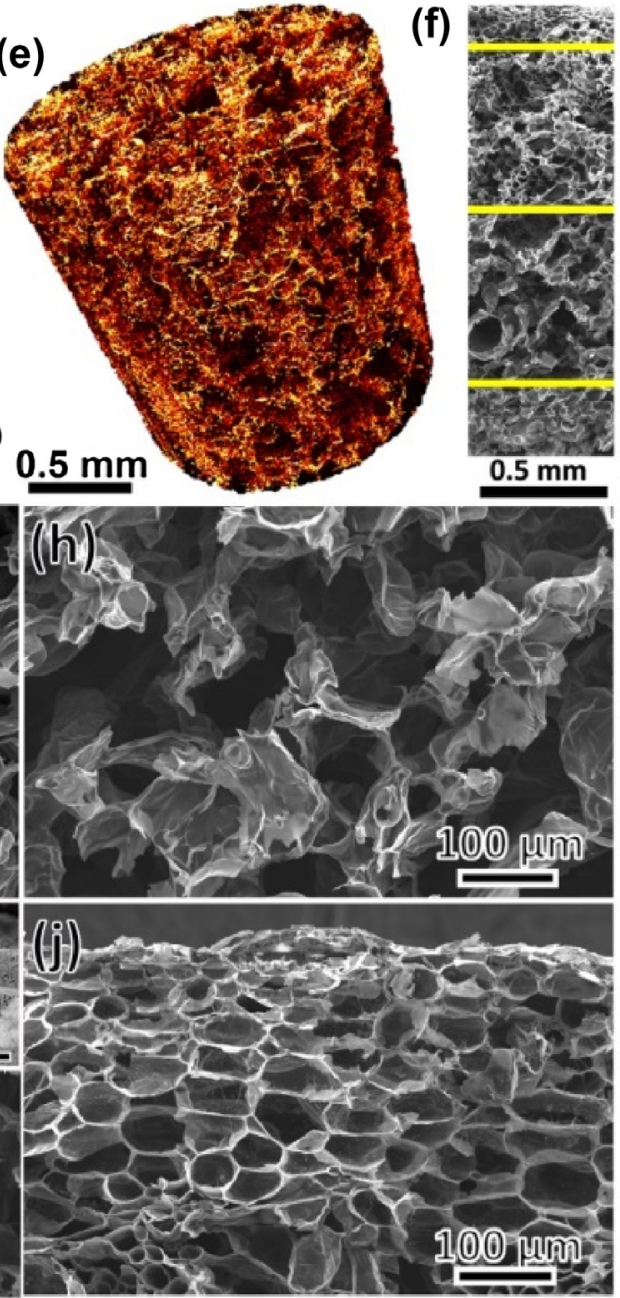

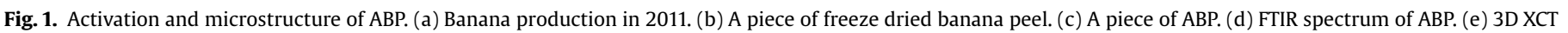

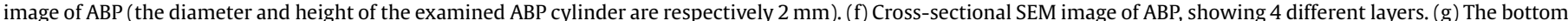

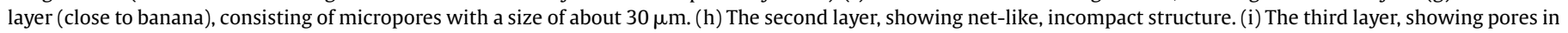
the net-like matrix. The inset shows a nanoporous thin film (scale bar $2 \mu \mathrm{m}$ ). (j) The outmost layer with compact porous structure.

Please cite this article in press as: Y. Zhang, et al., High-performance supercapacitors and batteries derived from activated banana-peel with porous structures, Electrochim. Acta (2016), http://dx.doi.org/10.1016/j.electacta.2016.11.099 
since the carbon scaffold complements the low conductivity of metal oxides, and spontaneously stimulates the capacity potential of metal oxides [20-25]. Among numerous battery-type pseudo-capacitive metal oxides for supercapacitors, needlelike nickel cobaltite $\left(\mathrm{NiCO}_{2} \mathrm{O}_{4}\right)$ has stimulated great interest because of its high theoretical capacity, low cost, and natural abundance [26-28]. Compared with supercapacitors, rechargeable lithium ion batteries are more popular as energy storage devices in our daily life. Although lithium ion batteries have served us for many years [29,30], recently produced electric cars and large screen electronic devices require higher specific capacity, which is beyond the capacity of conventional lithium-ion batteries [31]. To meet these goals, scientists and engineers are striving to develop next-generation high-energy batteries for electric vehicles and smart grids. Lithium-sulfur possesses a high theoretical specific capacity $1675 \mathrm{mAh} \mathrm{g}^{-1}$ and an ultrahigh energy density of $2600 \mathrm{Wh} \mathrm{kg}^{-1}$, making it a promising candidate to satisfy the needs for high energy batteries [32,33]. However, the rapid capacity decay, poor cyclic life, low coulombic efficiency due to the insulating nature of elemental sulfur $(\sim 5 \times 10$ $-30 \mathrm{Scm}^{-1}$ at room temperature), large volume change, and high dissolution of lithium polysulfides $\left(\mathrm{Li}_{2} \mathrm{~S}_{\mathrm{x}}, \mathrm{x}>2\right)$ ) have seriously impeded the development of lithium-sulfur batteries [34]. In addition, cost is another important factor that must be considered in the commercialization of lithium batteries. According to the US Advanced Battery Consortium report, the target price is $\$ 150$ per $\mathrm{kW} /$ $\mathrm{h}$ for lithium batteries [31]. Many efforts and improvements (in terms of cell component materials, structure design, and redox chemistry) have been made to address the aforementioned problems with lithium-sulfur batteries. One of the most effective methods to resolve these well-known problems is to combine sulfur with conductive carbon such as graphene, carbon nanotubes or porous carbon to produce a sulfur-carbon composite, which can fill the short of the poor conductivity of sulfur and simultaneously enhance sulfur utilization $[9,35,36]$. Although some advances have been made, the performance and cost of lithium-sulfur batteries are still, at large extent, unsatisfactory.

Here we report a simple and low cost two-step procedure to convert waste banana peels into conductive porous carbon scaffolds. First, a piece of banana peel was freeze dried to preserve the natural porous structure. The following-up high temperature annealing process converted the freeze dried banana peel into activated banana peel (ABP). The hierarchically porous architecture of the ABP scaffold improved the accessibility of electrolyte and electroactive materials while retaining its conductivity and mechanical robustness, making the ABP an electrochemical active material for free-standing electrode for energy storage applications. To demonstrate their unprecedented potential for energy storage applications, urchin-like $\mathrm{NiCO}_{2} \mathrm{O}_{4}$ nanowires and sulfur nanoparticles were anchored on the conductive ABP scaffolds to build high-performance electrode materials for supercapacitors and batteries, respectively. The assembled asymmetric supercapacitors based on ABP exhibited superior energy density and rate capacity. Nano sized pores were created by annealing the $\mathrm{Ni}\left(\mathrm{NO}_{3}\right)_{2}$ solution-treated ABP. Such nanoporous architecture effectively improved the utilization of sulfur and electrochemical performance of the as-assembled lithium-sulfur ( $\mathrm{Li}-\mathrm{S}$ ) batteries. The synergetic effects between the hierarchically porous carbon scaffolds and the active materials enabled the superior electrochemical performance and utilization of active materials $\left(\mathrm{NiCO}_{2} \mathrm{O}_{4}\right.$ and sulfur) for both supercapacitor and Li-S battery applications. Considering the unparalleled economic and social benefits of recycling waste banana peels, banana-peel derived porous carbon electrodes can pave the way to next-generation, low-cost energy storage devices. The novel hierarchically porous architecture of ABP should find more applications in high-performance energy storage devices.

\section{Experimental}

\subsection{Activation of banana peels}

Banana peels were cut into $20 \mathrm{~mm} \times 30 \mathrm{~mm}$ rectangular pieces (for supercapacitors) or punched to $15 \mathrm{~mm}$ diameter round pieces (for batteries) and frozen in a freezer before degradation without further treatment. The frozen pieces were then lyophilized in a freeze dryer for $3 \mathrm{~h}$. Next, the freeze-dried pieces were inserted into a horizontal tube furnace and heated at $900{ }^{\circ} \mathrm{C}$ for $1 \mathrm{~h}$ with continuous argon gas flow to convert the banana peel pieces into activated carbon. After carbonization, banana peel pieces shrank about $15 \%$ in size. Finally, the activated banana peel (ABP) pieces were washed with distilled water several times and subsequently dried at $75^{\circ} \mathrm{C}$ for $2 \mathrm{~h}$.

\subsection{Fabrication of ABP based supercapacitors and Li-S batteries}

A mild hydrothermal process was used to grow $\mathrm{NiCO}_{2} \mathrm{O}_{4}$ nanowires on $A B P$ to obtain high performance $\mathrm{ABP} / \mathrm{NiCO}_{2} \mathrm{O}_{4}$ electrode material for supercapacitor application. Typically, $0.145 \mathrm{~g}$ of $\mathrm{Ni}\left(\mathrm{NO}_{3}\right)_{2} \cdot 6 \mathrm{H}_{2} \mathrm{O}, 0.0725 \mathrm{~g}$ of $\mathrm{Co}\left(\mathrm{NO}_{3}\right)_{2} \cdot 6 \mathrm{H}_{2} \mathrm{O}$, and $0.45 \mathrm{~g}$ of urea were dissolved in $40 \mathrm{~mL}$ of distilled water to form a light pink solution. The solution was then transferred into a $50 \mathrm{~mL}$ Teflon-lined stainless steel autoclave and a piece of ABP (about $17 \mathrm{~mm} \times 25 \mathrm{~mm}, 0.1 \mathrm{~g}$ ) was vertically suspended in the solution. The autoclave was kept at $120^{\circ} \mathrm{C}$ in an electric oven for $3 \mathrm{~h}$. Finally, the products were taken out and washed with distilled water several times before being dried at $75^{\circ} \mathrm{C}$ for $2 \mathrm{~h}$, after which they were annealed at $350^{\circ} \mathrm{C}$ in an Argon atmosphere for $2 \mathrm{~h}$ to produce $\mathrm{NiCO}_{2} \mathrm{O}_{4}$ nanowires. For the three-electrode system, the synthesized $\mathrm{ABP}$ and $\mathrm{ABP} / \mathrm{NiCO}_{2} \mathrm{O}_{4}$ were directly used as working electrodes, a piece of platinum foil $(10 \mathrm{~mm} \times 20 \mathrm{~mm})$ and a saturated calomel electrode (SCE) were used as the counter and reference electrodes, respectively, and $6 \mathrm{M}$ aqueous $\mathrm{KOH}$ solution was used as an electrolyte. Asymmetric supercapacitors were assembled by using the $\mathrm{ABP} / \mathrm{NiCO}_{2} \mathrm{O}_{4}$ as the positive electrode, commensurate $\mathrm{ABP}$ as the negative electrode, stainless steel foil as the current collector and polyvinyl alcohol (PVA)/KOH gel film as both the separator and electrolyte. The PVA/KOH gel was obtained by mixing 3 grams of $\mathrm{KOH}$ and 6 grams of PVA in $60 \mathrm{~mL}$ of deionized water at $80^{\circ} \mathrm{C}$ under stirring until the solution became clear. The solution was then poured onto a flat petri dish to form a thin $\mathrm{KOH} / \mathrm{PVA}$ film via natural solidification.

For the fabrication of lithium-sulfur batteries, round ABP pieces were immersed into $0.3 \mathrm{M} \mathrm{Ni}\left(\mathrm{NO}_{3}\right)_{2}$ solution and then dried at $70{ }^{\circ} \mathrm{C}$ for $2 \mathrm{~h}$. The $\mathrm{Ni}\left(\mathrm{NO}_{3}\right)_{2}$ treated pieces were heated at $1000^{\circ} \mathrm{C}$ with the protection of inert gas to create nanopores and graphene wrapped $\mathrm{Ni}$ nanoparticles on the cell walls of ABP. Sulfur was deposited onto the $\mathrm{ABP} / \mathrm{Ni} /$ graphene by heating the sulfur-loaded $\mathrm{ABP} / \mathrm{Ni} /$ graphene at $155^{\circ} \mathrm{C}$ for $12 \mathrm{~h}$ and then at $200^{\circ} \mathrm{C}$ for $2 \mathrm{~h}$ in a sealed Teflon-lined stainless steel autoclave. The electrolyte was produced by dissolving $1 \mathrm{~mol} / \mathrm{L}$ LiTFSI and $1 \mathrm{~mol} / \mathrm{L} \mathrm{LiNO}_{3}$ in an organic solvent of dimethoxyethane (DME) +1,3-dioxolane (DOL) at a 1:1 volume ratio. Lithium metal was used as anode and Celgard 2400 film as separator. The CR2032 coin cell was assembled with a MTI MSK-110 crimping machine in an argon-filled glove box (M. Braun, Germany) with oxygen and water contents below 0.1 and $0.1 \mathrm{ppm}$, respectively.

\subsection{Materials characterization}

The as-prepared ABP and as-drived electrodes were characterized by X-ray diffraction (XRD, a PANalytical X'Pert Pro MultiPurpose Diffractometer (MPD) equipped with $\mathrm{Cu} \mathrm{K}_{\alpha}$ radiation $(\lambda=0.15406 \mathrm{~nm})$ ), scanning electron microscopy (SEM, FEI Quanta 
650 with EDS detector), transmission electron microscopy (TEM, JEOL 2000FX), high resolution transmission electron microscopy (HRTEM, FEI Titan), Fourier transform infrared spectroscopy (FTIR, Nicolet iS5 IR spectrometer), Raman spectroscopy (a Renishaw inVia Raman microscope at the wave length of $785 \mathrm{~nm}$ ), and X-ray computed tomography (XCT, Xradia MicroXCT-200). The specific area and pore size of $\mathrm{ABP}$ and its electrodes were measured using a Quantachrom Autososrb iQ nitrogen adsorption-desorption analyzer and measured with the Brunauer-Emmett-Teller (BET) theory.

\subsection{Electrochemical characterizations}

The electrochemical properties of supercapacitor electrodes were measured with both three-electrode and two-electrode electrochemical systems using a CHI 660E electrochemical workstation. Cyclic voltammetry $(\mathrm{CV})$ tests were performed at scan rates ranging from 10 to $50 \mathrm{mV} \mathrm{s}^{-1}$. Galvanostatic (GV) charge/ discharge curves were obtained at different current densities. Electrochemical impedance spectra (EIS) were measured in the frequency range from $100 \mathrm{KHz}$ to $1 \mathrm{~Hz}$ with an AC perturbation of $5 \mathrm{mV}$. ABP based Li-S batteries were assembled using a CR2032 coin cell. A LAND CT2003A battery test instrument was used to perform galvanostatic charge/discharge measurements. The CV and EIS in the frequency range from $100 \mathrm{kHz}$ to $1 \mathrm{~Hz}$ with an AC perturbation of $5 \mathrm{mV}$ were performed with a CHI 660E electrochemical workstation.

\section{Results and discussion}

\subsection{Activation of banana peels}

A banana from Guatemala was used as the raw material without further treatment. Considering the mass production of bananas
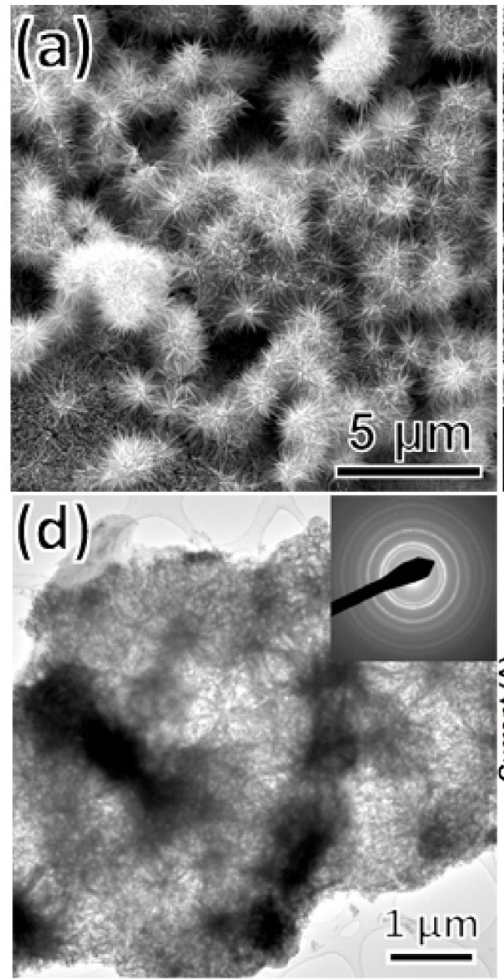

(g)

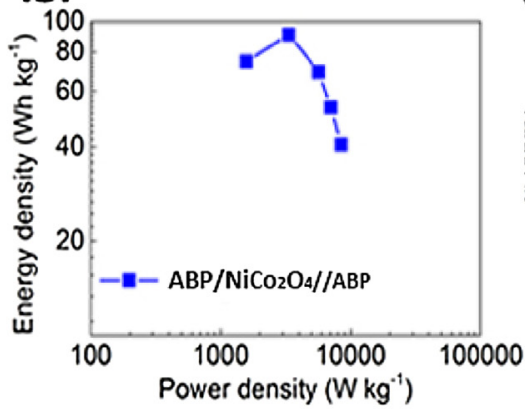

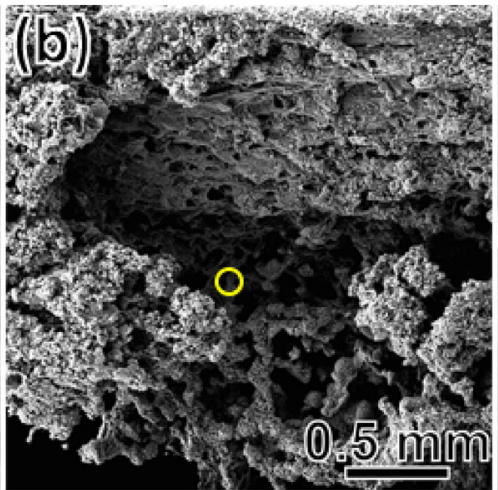

(e)

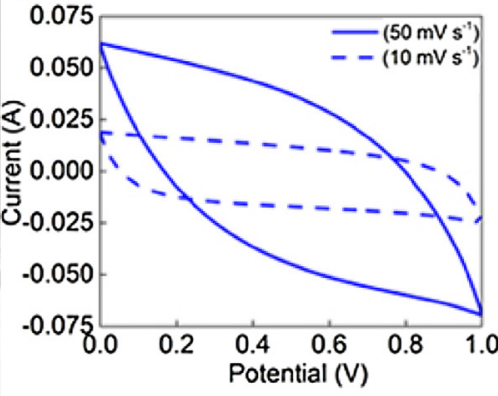

(h)

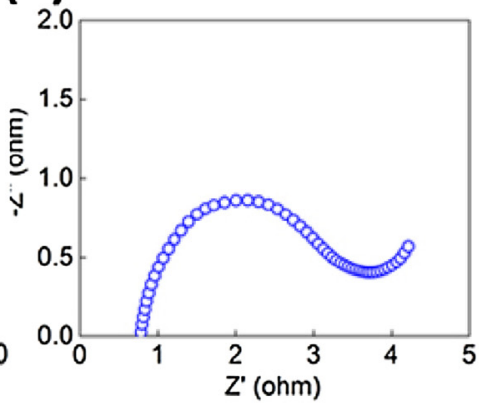

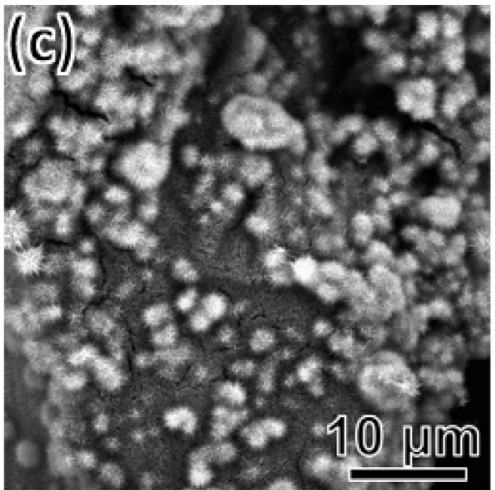

(f)

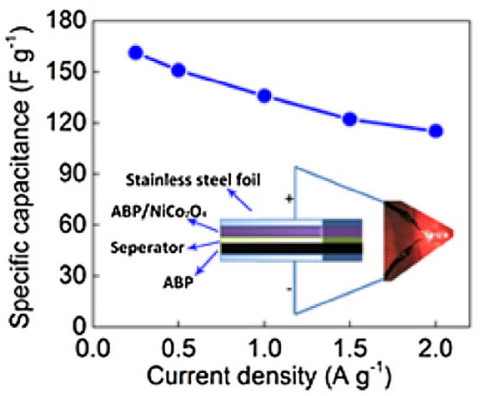

(i)

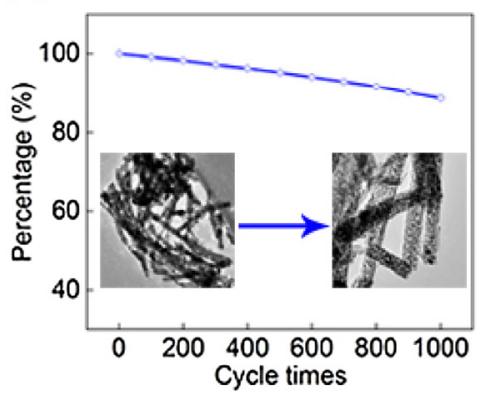

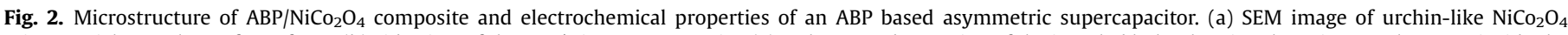

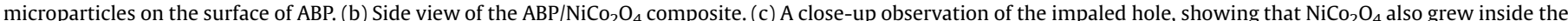

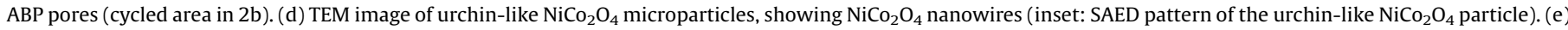

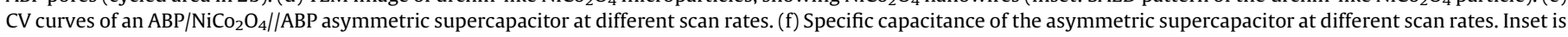

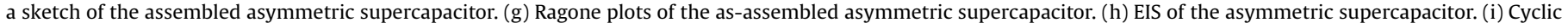

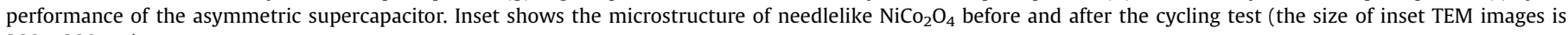
$280 \times 280 \mathrm{~nm})$.

Please cite this article in press as: Y. Zhang, et al., High-performance supercapacitors and batteries derived from activated banana-peel with porous structures, Electrochim. Acta (2016), http://dx.doi.org/10.1016/j.electacta.2016.11.099 
and waste banana peels (Fig. 1a), recycling surplus and abandoned banana peels is economically and socially significant. After the freeze-drying process, the banana peel pieces preserved their original architectures but were dehydrated (Fig. 1b). The subsequent heating process at $900{ }^{\circ} \mathrm{C}$ for $1 \mathrm{~h}$ with continuous argon gas flow converted the banana peel pieces into activated carbon with dark black color (Fig. 1c). Comparing with the freeze dried banana peel pieces, activated banana peel (ABP) pieces shrank about $15 \%$. For rectangular pieces, $A B P$ pieces process a width of $15-18 \mathrm{~mm}$, length of $24-27 \mathrm{~mm}$, and thickness of 3-4 mm. For round pieces, ABP pieces have a diameter of $13 \mathrm{~mm}$ and a thickness of 3-4 mm. The density of $A B P$ ranges from $0.08 \mathrm{~g} \mathrm{~cm}^{-3}$ to $0.13 \mathrm{~g} \mathrm{~cm}^{-3}$, depending on the raw materials. The ABP from mature bananas often exhibits slightly higher densities, which may be ascribed to a higher concentration of sugar and more extensive dehydration. Therefore, rectangular pieces have a weight about $0.1 \mathrm{~g}(0.09$ $0.12 \mathrm{~g})$ and round pieces have a weight about $0.04 \mathrm{~g}(0.036-$ $0.045 \mathrm{~g}$ ). The electrical resistance of the activated banana peel (ABP) was measured (by multimeter) to be $17.7 \Omega$. Statistically, the sheet resistance of ABP ranges from 7.5-16.5 $\Omega \mathrm{sq}^{-1}$. There were no obvious peaks beyond $1500 \mathrm{~cm}^{-1}$ in the Fourier transform infrared spectroscopy (FTIR) spectrum of ABP (Fig. 1d). Several peaks located in between 600 to $1500 \mathrm{~cm}^{-1}$ were attributed to $\mathrm{C}-\mathrm{H}$, $\mathrm{C}-\mathrm{N}$, and $\mathrm{C}-\mathrm{O}$ bonds, indicating $\mathrm{ABP}$ is not pure carbon but also contains other elements like $\mathrm{H}, \mathrm{O}$ and $\mathrm{N}$. This result is constant with other researches about activated banana peels [15-19]. ABP's Raman spectrum exhibited a broad G bond at $\sim 1580 \mathrm{~cm}^{-1}$ and $D$ bond at $1350 \mathrm{~cm}^{-1}$ (see Fig. S1 in Supplementary data). The G band and $\mathrm{D}$ band are assigned to the hexagonal carbon plane and crystal defects or imperfections, respectively. The ratio of the relative intensity of these two bands $\left(\mathrm{I}_{\mathrm{D}} / \mathrm{I}_{\mathrm{G}}\right)$ is proportional to the number of defect sites in the graphite carbon. Different from the sharp $G$ bonds and low $\mathrm{I}_{\mathrm{D}} / \mathrm{I}_{\mathrm{G}}$ values of graphite and graphene, the obvious broad $\mathrm{D}$ bonds and high $\mathrm{I}_{\mathrm{D}} / \mathrm{I}_{\mathrm{G}}$ values of $\mathrm{ABP}$ pointed towards the amorphous carbon with relative low graphitization.

\subsection{Microstructure of $A B P$}

The reconstructed three dimensional X-ray computed tomography (XCT) image (Fig. 1e) and low magnification scanning electron microscope (SEM) image (Fig. 1f) of ABP exhibited an incompact and multi-layered architecture with 4 different layers from the inside out. The inner layer (closest to the banana) possessed orderly arranged macropores with the size of approximately $30 \mu \mathrm{m}$ (Fig. 1g). The second layer moving outward showed a loose and net-like structure (Fig. $1 \mathrm{~h}$ ). The third layer out showed a combination of fiber bundles and thin nanoporous films with a net-like matrix (Fig. 1i). The outermost layer consisted of smaller compact pores with a size of about $20 \mu \mathrm{m}$, originating from the outer epidermal cells of the peel (Fig. 1j) [37]. The microstructure of banana peel displayed an obvious transition from loosely interconnected pores to densely arranged pores. Such loose-dense structural configuration is expected to improve the performance of energy storage devices because the loosely interconnected pores are able to enhance the accessibility of electrolyte and active material whereas the compact layer can retain the conductivity and mechanical robustness. The porous structure of this ABP resulted in a large Brunauer-Emmet-Teller (BET) [38] surface area of $194 \mathrm{~m}^{2} \mathrm{~g}^{-1}$ and low density $\left(0.094 \mathrm{~g} \mathrm{~cm}^{-3}\right)$. The obtained BET surface area is higher than the carbonized banana fiber $\left(36 \mathrm{~m}^{2} \mathrm{~g}^{-1}\right)$ [15], banana peel $\left(14.5-33 \mathrm{~m}^{2} \mathrm{~g}^{-1}\right)$ [17], and zinc nitrite treated banana peel $\left(131 \mathrm{~m}^{2} \mathrm{~g}^{-1}\right)$ [16] because banana peels were freeze dried before dehydration and degradation so that the original porous structure was reversed. Without freeze-drying ABP architectures would collapse during activation, leading to a structure without definite shape (Fig. S2) and a low specific surface area of $31 \mathrm{~m}^{2} \mathrm{~g}^{-1}$, which is close to the reported directly pyrolytic banana fiber and banana peel $[15,17]$. To study the structural variation of bananas from different locations, three other bananas from Costa Rica, Colombia, and Ecuador were inspected by SEM. Banana peels from various locations exhibited almost identical porous microstructure with minor differences, which are negligible when being used as electrodes. Therefore, banana peel is naturally porous with high specific surface area and interconnected microstructure even without further chemical treatment. It can be used as free-standing electrodes directly but has much larger potential as electroactive material carriers.

\subsection{Supercapacitors from $A B P$}

To demonstrate the potential of banana-peel derived activated carbon in energy storage applications, ABP (about $4 \mathrm{~cm}^{2}$ in area) was directly used as an electrode in a three-electrode system for supercapacitor application and exhibited acceptable double-layer capacitance because of the relative large surface area (Fig. S3). More importantly, the multi-layered, hierarchically porous architecture makes ABP an ideal supporting backbone to composite with other active materials. A mild hydrothermal process was used to grow $\mathrm{NiCO}_{2} \mathrm{O}_{4}$ nanowires in-situ on the ABP. Fig. 2a shows a representative SEM image of the $\mathrm{ABP} / \mathrm{NiCO}_{2} \mathrm{O}_{4}$ hybrid in which urchin-like $\mathrm{NiCO}_{2} \mathrm{O}_{4}$ micron sized particles (comprised of needlelike $\mathrm{NiCO}_{2} \mathrm{O}_{4}$ nanowires (Fig. S4a and b)) were uniformly coated on the surface of ABP. The urchin-like morphology is expected to facilitate ion diffusion and electron transfer. Moreover, not only the surface but also the inside pores of $\mathrm{ABP}$ were covered by $\mathrm{NiCO}_{2} \mathrm{O}_{4}$ nanowires, which can be attributed to the ABP's 3D net-like architecture that promoted the infiltration of reactants into the inner cavities of ABP during the hydrothermal reaction (Fig. 2b and c). Fig. $2 \mathrm{~d}$ shows the transmission electron microscopy (TEM) image and corresponding selected area electron diffraction (SAED) pattern of $\mathrm{NiCO}_{2} \mathrm{O}_{4}$ microparticles, demonstrating that the urchinlike $\mathrm{NiCO}_{2} \mathrm{O}_{4}$ microparticles were actually comprised of $\mathrm{NiCO}_{2} \mathrm{O}_{4}$ nanowires. The spotty diffraction rings with messy character suggested that polycrystalline and amorphous phases coexisted in the $\mathrm{NiCo}_{2} \mathrm{O}_{4}$ nanowires, which was in good agreement with the poor crystallinity observed in the XRD (Fig. S5). Close-up observation (Fig. S4c and d) unveiled that the $\mathrm{NiCO}_{2} \mathrm{O}_{4}$ nanowires had a length of about $500 \mathrm{~nm}$ and diameter of about $20 \mathrm{~nm}$; individual $\mathrm{NiCo}_{2} \mathrm{O}_{4}$ nanowires were comprised of small grains with 2-4 nm nanopores, not only increasing the surface areas but also enhancing the pseudo-capacitance of the electrode. The BET specific surface area of $\mathrm{ABP} / \mathrm{NiCO}_{2} \mathrm{O}_{4}$ electrode reached $729.03 \mathrm{~m}^{2} \mathrm{~g}^{-1}$ but that of $\mathrm{NiCO}_{2} \mathrm{O}_{4}$ powder was only $211.61 \mathrm{~m}^{2} \mathrm{~g}^{-1}$, indicating that to composite $\mathrm{NiCO}_{2} \mathrm{O}_{4}$ with $\mathrm{ABP}$ effectively inhibited the aggregation of nanowires. The electrochemical performance of $\mathrm{NiCO}_{2} \mathrm{O}_{4} / \mathrm{ABP}$ electrodes in the threeelectrode system was significantly enhanced, as demonstrated by the increased current response in the cyclic voltammetry (CV) curves and the prolonged discharge period in the galvanostatic (GV) charge/discharge curves (Fig. S6a and b). Overall, the $\mathrm{NiCo}_{2} \mathrm{O}_{4} /$ ABP hybrid electrode showed three times higher specific capacitance than the ABP electrode (Fig. S3). The $\mathrm{ABP} / \mathrm{NiCO}_{2} \mathrm{O}_{4}$ hybrid electrode exhibited high specific capacitances of 218.6, 188.1,166.3, 143.2 , and $132.8 \mathrm{~F} / \mathrm{g}$ at the current densities of $1,2,5,10$, and $15 \mathrm{~mA} \mathrm{~cm}^{-2}$, respectively (Fig. S6c). In fact, the specific capacitances of $\mathrm{NiCO}_{2} \mathrm{O}_{4}$ in the ABP hybrid electrode reached $1670.3 \mathrm{Fg}^{-1}$ (based on the mass of $\mathrm{NiCO}_{2} \mathrm{O}_{4}$ alone) (Fig. S6d). It is noteworthy that the equivalent series resistance (ESR) of the $\mathrm{NiCO}_{2} \mathrm{O}_{4} / \mathrm{ABP}$ electrode (Fig. S6e) is almost the same as that of the pure ABP electrode (Fig. S3d) but the charge transfer resistance $(R c t)$ is smaller, indicating that the hierarchical microstructure of the urchin-like $\mathrm{NiCO}_{2} \mathrm{O}_{4}$ further shortened the ion diffusion path and 
enhanced ion transfer. Therefore, $\mathrm{ABP}$ and $\mathrm{NiCo}_{2} \mathrm{O}_{4}$ are mutually enhanced. $\mathrm{ABP}$ provided an interconnected porous framework for $\mathrm{NiCO}_{2} \mathrm{O}_{4}$ nanowires, stimulating the formation of urchin-like particles, inhibiting aggregation, and increasing electrolyte accessibility. $\mathrm{NiCO}_{2} \mathrm{O}_{4}$, in return, effectively improved the capacitance of ABP electrodes and reduced the Rct. Banana peels were considered as a porous carbon source and derived supercapacitors exhibited impressive electric double-layer capacities [15-17], but the potential to be highly conductive, porous carbon scaffold for other active materials was largely overlooked.

Since three-electrode system focuses on electrochemical properties of single electrode and cannot reflect the real-life performances of an energy storage application, asymmetric supercapacitors were assembled to examine the practical utilization of the banana peel-based supercapacitors. ABP was used as the negative electrode and the $\mathrm{ABP} / \mathrm{NiCO}_{2} \mathrm{O}_{4}$ composite as the positive electrode, while PVA/KOH gel served as both the solid electrolyte and separator (the $\mathrm{PVA} / \mathrm{KOH}$ gel was prepared as previously reported [38]) (see the inset in Fig. 2f). No distortion was found in the CV curves of the ABP asymmetric supercapacitor at the low scan rate regime, indicating the excellent synergistic effects between the double-layer capacitive $A B P$ and battery-type pseudo-capacitive $\mathrm{NiCO}_{2} \mathrm{O}_{4}$ (Fig. 2e). The specific capacitances of the ABP based asymmetric supercapacitor were measured to be $161.1 \mathrm{~F} \mathrm{~g}^{-1}$ at $0.25 \mathrm{Ag}^{-1}$ and $115.1 \mathrm{Fg}^{-1}$ at $2 \mathrm{Ag}^{-1}$ with a capacitance retention rate of $71.44 \%$ (even with an 8 fold increase in current density), indicating excellent rate performance (Fig. 2f). Energy density and power density are usually gained at the expense of another. Generally, carbon based double layer supercapacitors exhibit high power density while metal oxides based pseudo supercapacitors deliver high energy density. However, an ideal supercapacitor for energy storage purpose is to provide high energy density at the high charge/discharge rate regime (power density). The energy density and power density of the ABP asymmetric supercapacitors are plotted in Fig. $2 \mathrm{~g}$. The ABP based asymmetric supercapacitor showed eminent performance with a high retained energy density of $40.7 \mathrm{Wh} \mathrm{kg}^{-1}$ at a high power density of $8.4 \mathrm{~kW} \mathrm{~kg}^{-1}$, indicating a mutual promotion of $\mathrm{ABP}$ scaffold and $\mathrm{NiCo}_{2} \mathrm{O}_{4}$ nanowires. Fig. $2 \mathrm{~h}$ shows the electrochemical impedance spectroscopy (EIS) plots of the asymmetric supercapacitor, which exhibited similar tendency as it was in the threeelectrode system. The slightly large $R_{c t}$ of $\mathrm{ABP}$ asymmetric supercapacitor is ascribed to the higher loading of $\mathrm{NiCO}_{2} \mathrm{O}_{4}$ and less compact ABP structure. Fig. $2 \mathrm{i}$ shows the cyclic performance of the assembled asymmetric supercapacitor, which was carried out by GV cyclic tests for over 1000 cycles at a current density of $15 \mathrm{mAcm}^{-2}$. Results showed that the ABP-based asymmetric supercapacitor had a capacitance retention rate of $88.7 \%$ after 1000 cycles. The decay of specific capacitance can be ascribed to the following two factors: the exfoliation of $\mathrm{ABP}$ and $\mathrm{NiCO}_{2} \mathrm{O}_{4}$ nanowires (Fig. S7a), and the segregation and aggregation of $\mathrm{NiCO}_{2} \mathrm{O}_{4}$ particles during cycling (Fig. S7b-d). In fact, needlelike $\mathrm{NiCO}_{2} \mathrm{O}_{4}$ nanowires grew nearly two times in size after 1000 cycles, as shown by comparing the TEM images of pristine $\mathrm{NiCO}_{2} \mathrm{O}_{4}$ nanowires and the nanowires after 1000 cycles (see the insets in Figs. $2 \mathrm{i}$ and S7c and d). The swelling led to a reduction in electroactive sites and weakened redox chemistry. Worth mentioning is that although the loose upper layers of ABP degraded after 1000 cycles, the electrode remained excellent structural integrity without pulverization because the compact bottom layer prevented the ABP from catastrophic damage. Thus, the hierarchical architecture of ABP was found to enhance the high performance of supercapacitors. Compared with other pseudo supercapacitors on various substrates [39-42], the banana-peel based supercapacitors exhibit superior capacity and energy density, competitive power density and cycle ability.

\subsection{Li-S batteries from $A B P$}

Sulfur powders were first loaded onto a piece of ABP. The sulfur loaded ABP was then annealed at $155^{\circ} \mathrm{C}$ for $12 \mathrm{~h}$ and at $200^{\circ} \mathrm{C}$ for $2 \mathrm{~h}$ to infiltrate sulfur into the pores of $\mathrm{ABP}$ and coat a sulfur layer
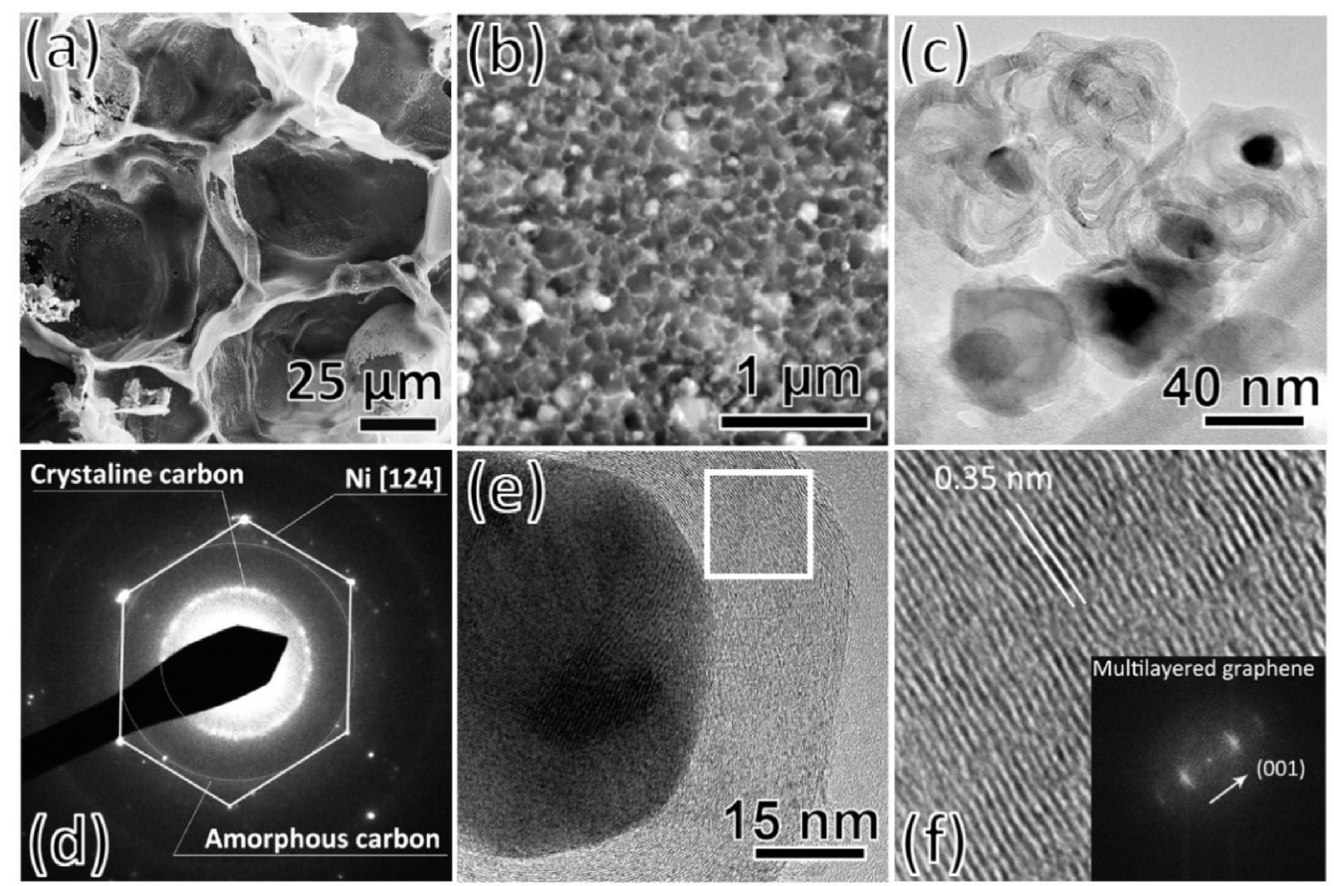

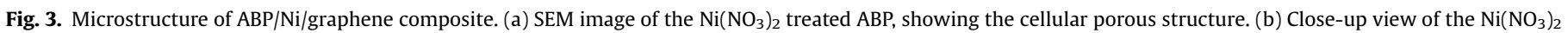

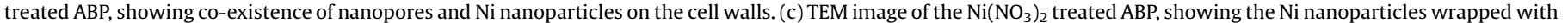

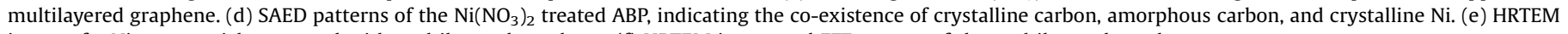
image of a Ni nanoparticle wrapped with multilayered graphene. (f) HRTEM image and FFT pattern of the multilayered graphene.

Please cite this article in press as: Y. Zhang, et al., High-performance supercapacitors and batteries derived from activated banana-peel with porous structures, Electrochim. Acta (2016), http://dx.doi.org/10.1016/j.electacta.2016.11.099 
on the ABP surface without agglomeration (Fig. S8). The sulfur loading was measured to be $\sim 2.3 \mathrm{mg} \mathrm{cm}^{-2}$, which is comparable with that reported in literatures [43-46]. This is ascribed to the hierarchically porous structure in ABP that enhanced sulfur loading. The $\mathrm{ABP} / \mathrm{S}$ (as the cathode) was assembled with lithium (as the anode) into a Li-S battery. This Li-ABP/S battery achieved a specific capacity of $1205 \mathrm{mAh} \mathrm{g}^{-1}$ in the first discharge (Fig. S9). In the second cycle, however, the capacity dropped abruptly down to $\sim 600 \mathrm{mAh} \mathrm{g}^{-1}$. After 50 cycles, the capacity stabilized at $\sim 450$ $\mathrm{mAh}^{-1}$

To overcome the fast capacity decay and the low utilization of sulfur, we created nanosized pores and deposited Ni/graphene nanoparticles simultaneously on the cell walls of ABP via a simple, low cost chemical route using $\mathrm{Ni}\left(\mathrm{NO}_{3}\right)_{2}$ solution. The $\mathrm{Ni}\left(\mathrm{NO}_{3}\right)_{2}$ treated $\mathrm{ABP}$ decomposed into the following products during the heat treatment at $1000{ }^{\circ} \mathrm{C}$ [47]:

$\mathrm{Ni}\left(\mathrm{NO}_{3}\right)_{2} \cdot 2 \mathrm{H}_{2} \mathrm{O} \rightarrow \mathrm{Ni}\left(\mathrm{NO}_{3}\right)(\mathrm{OH})_{2} \cdot \mathrm{H}_{2} \mathrm{O}+\mathrm{NO}_{2}$

$\mathrm{Ni}\left(\mathrm{NO}_{3}\right)(\mathrm{OH})_{1.5} \mathrm{O}_{0.25} \cdot \mathrm{H}_{2} \mathrm{O} \rightarrow 0.5 \mathrm{Ni}_{2} \mathrm{O}_{3}+\mathrm{HNO}_{3}+1.25 \mathrm{H}_{2} \mathrm{O}$

$3 \mathrm{Ni}_{2} \mathrm{O}_{3} \rightarrow 2 \mathrm{Ni}_{3} \mathrm{O}_{4}+0.5 \mathrm{O}_{2}$

$\mathrm{Ni}_{3} \mathrm{O}_{4} \rightarrow 3 \mathrm{NiO}+0.5 \mathrm{O}_{2}$

$\mathrm{NiO}+\mathrm{C} \rightarrow \mathrm{Ni}+\mathrm{CO}$
$\mathrm{NiO}+\mathrm{CO} \rightarrow \mathrm{Ni}+\mathrm{CO}_{2}$

Among the decomposed products, the corrosive $\mathrm{HNO}_{3}$ vapors etched the ABP surface, creating nanoporous structure with an average pore size of $30 \mathrm{~nm}$ while the original cell structure remained (Fig. 3a and b). A close-up inspection of the $\mathrm{Ni}\left(\mathrm{NO}_{3}\right)_{2}$ treated $\mathrm{ABP}$ revealed that $\mathrm{Ni}$ nanoparticles were embedded in nano carbon rings (Fig. $3 \mathrm{c}$ ). In addition to $\mathrm{Ni}$ and amorphous $\mathrm{C}$, the SAED pattern validated the existence of $\mathrm{C}$ crystal (Fig. 3d). High resolution TEM (HRTEM) image shows that $\mathrm{Ni}$ nanoparticles were wrapped with multilayered graphene, forming Ni/graphene core/ shell structure (Fig. 3e and f). At high temperature, the $\mathrm{C}$ atoms from $\mathrm{ABP}$ dissolved into $\mathrm{Ni}$. When the sample cooled down to room temperature, the $C$ atoms precipitated out and segregated on the $\mathrm{Ni}$ nanoparticle surface, forming multilayered graphene shell $[48,49]$. This $\mathrm{ABP} / \mathrm{Ni} /$ graphene composite demonstrated an improved conductivity with a sheet resistance of $7.4 \Omega \mathrm{sq}^{-1}$. The conductivity improvement can be ascribed to the graphene-wrapped-Ninanoparticles because nickel and graphene are both excellent conductors. The $\mathrm{ABP} / \mathrm{Ni} /$ graphene has a specific area of $474 \mathrm{~m}^{2} \mathrm{~g}^{-1}$, 2.5 times larger than $\mathrm{ABP}\left(194 \mathrm{~m}^{2} \mathrm{~g}^{-1}\right)$. The Barrett-Joyner-Halenda (BJH) pore size distribution (Fig. S10) showed that most of the pores in the $\mathrm{ABP} / \mathrm{Ni} /$ graphene were less than $40 \mathrm{~nm}$, in good agreement with the SEM observation (Fig. 3b). It is reported that core-shell nanoparticles with mesoporous structure could capture electroactive materials, enhance ion transfer, and buffer volume change, therefore effectively improve the performance of energy storage applications [50-52]. Thusly, the ABP/Ni/graphene hybrid with order arranged nanopores and $\mathrm{Ni} /$ graphene core/shell nanoparticles is expected to overcome the quick capacity decay and improve the specific capacity of Li-S batteries.

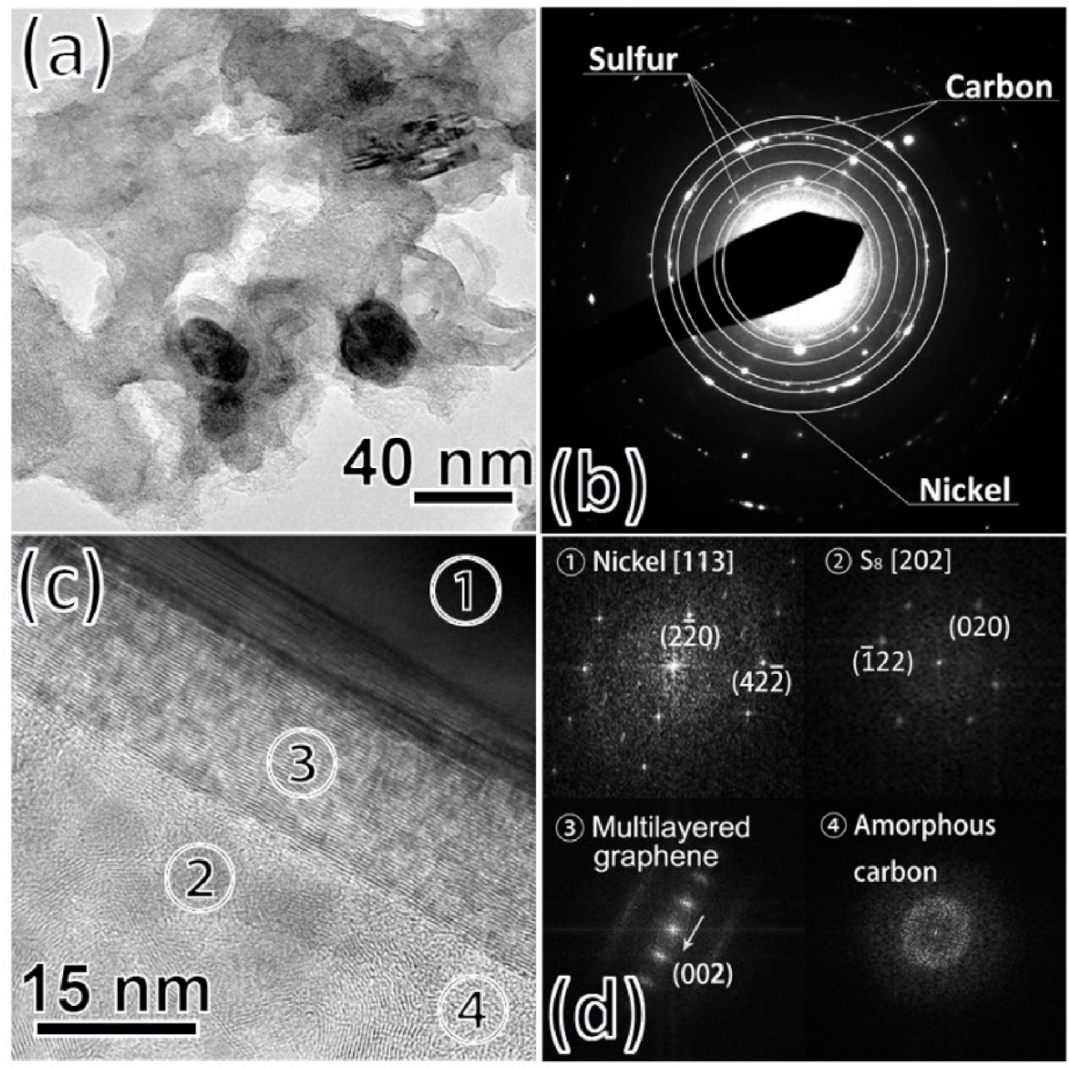

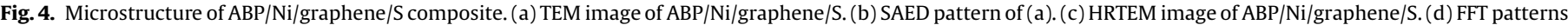

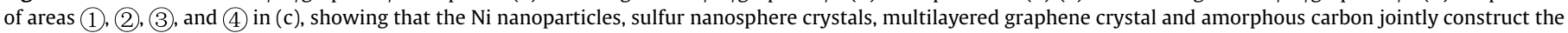
$\mathrm{ABP} / \mathrm{Ni} /$ graphene/S composite.

Please cite this article in press as: Y. Zhang, et al., High-performance supercapacitors and batteries derived from activated banana-peel with porous structures, Electrochim. Acta (2016), http://dx.doi.org/10.1016/j.electacta.2016.11.099 
Next, we used the ABP/Ni/graphene composite to load sulfur. Sulfur was homogeneously anchored on the $\mathrm{ABP} / \mathrm{Ni} /$ graphene scaffold with the sulfur loading of $5.3 \mathrm{mg} \mathrm{cm}^{-2}$ (Fig. S10), which is approximately two times higher than that of the untreated $A B P$ $\left(2.3 \mathrm{mg} \mathrm{cm}^{-2}\right)$. The enhancement of sulfur loading can be ascribed to the nanopores in the composite, which offer more sites for sulfur storage. The BET surface area decrease drastically to $23 \mathrm{~m}^{2} \mathrm{~g}^{-1}$, indicating $S$ filled the pores on the ABP walls, which was also proved by SEM image and EDS maps in Fig. S11. Low magnification TEM image (Fig. 4a) exhibited that sulfur filled into carbon rings in Fig. 3c. The corresponding SAED pattern validated the existence of sulfur polycrystals (Fig. 4b). The close-up HRTEM inspection (Fig. 4c) unveiled that the $\mathrm{Ni}$ nanoparticles were coated with multilayered graphene (inner shell) and polycrystalline sulfur (outer shell). The outer sulfur shell contained nanosphere $\mathrm{S}$ crystals with the size of $5 \mathrm{~nm}$ embedded in the amorphous $C$ (Fig. 4c), which should be the ABP matrix. The corresponding FFT patterns (Fig. 4d) confirmed that Ni nanoparticles, sulfur nanosphere crystals, multilayered graphene crystal and amorphous carbon jointly construct the $\mathrm{ABP} / \mathrm{Ni} /$ graphene/S composite, which was consistent with XRD result (Fig. S12). The close contact between $\mathrm{S}$, graphene, $\mathrm{Ni}$ and $\mathrm{ABP}$ in cellulose architecture is expected to increase conductivity and facilitate ion diffusion and electron transfer, therefore jointly enhancing the electrochemical performance of $\mathrm{Li}-\mathrm{ABP} / \mathrm{Ni} /$ graphene/S batteries. Fig. 5 shows the detailed processes to convert a banana peel into the $A B P / N i /$ graphene/S composite.

The most exciting development was the successful assembly of the $\mathrm{ABP} / \mathrm{Ni} /$ graphene/S (as the cathode) and lithium (as the anode) into a high-performance Li-S battery. Fig. 6a shows the typical charge/discharge curve of the Li-ABP/Ni/graphene/S battery. Four stages appear to exist during discharge process (Stage I to IV in Fig. 6a), which can be respectively ascribed to the formation of $\mathrm{S}_{3}{ }^{\bullet-}$ radical anion (Stage I: plateau at $2.3 \mathrm{~V}$ ), the formation of high-order polysufides from $\mathrm{S}_{3}{ }^{--}$(Stage II: dip between $2.3-2.1 \mathrm{~V}$ ), the transformation between $\mathrm{S}_{4}{ }^{2-}$ and $\mathrm{S}^{2-}$ (Stage III: plateau at $2.1 \mathrm{~V}$ ), and the formation of solid $\mathrm{Li}_{2} \mathrm{~S}$ (Stage IV: dip between 2.1-1.5 V) [53]. The charge process can be grouped into 3 stages (Stage V to VII in Fig. 6a). The first stage of charge process (Stage $\mathrm{V}$ ) represents the conversion from solid $\mathrm{Li}_{2} \mathrm{~S}$ to soluble low-order polysulfide $\left(\mathrm{S}_{2}{ }^{2-}\right)$. The plateau at $2.3-2.4 \mathrm{~V}$ (Stage $\mathrm{VI}$ ) can be ascribed to the transformation between low-order polysulfide $\left(\mathrm{S}_{2}{ }^{2-}\right.$ or $\left.\mathrm{S}_{4}{ }^{2-}\right)$ to high-order polysulfides $\left(\mathrm{S}_{8}{ }^{2-}\right.$ or $\left.\mathrm{S}_{6}{ }^{2-}\right)$ [53]. The last step of charge process (Stage VII in Fig. 6a) is a quick ascendance of voltage from $2.4 \mathrm{~V}$ to $2.8 \mathrm{~V}$, indicating the transformation of high-order polysulfides back to solid sulfur. It is noteworthy that the last stage (Stage IV) of the discharge process and the first stage of the charge process
(Stage V) both exhibited gentle slopes, rather than an abrupt dip or sudden jump which were often reported in Li-S batteries [43-46]. The gentle slopes in Stages IV and V are ascribed to the 3D hierarchically porous structure of ABP, in which the sulfur stored in the pores slowed down capacity decay. No $\mathrm{NiS}_{2}$ formed (Fig. 4 and S11) because the multilayered graphene obstructed the reactions between nickel and sulfur during charge/discharge cycling.

It is especially recognized that the $\mathrm{Li}-\mathrm{ABP} / \mathrm{Ni} /$ graphene/ $\mathrm{S}$ battery exhibited good rate ability (Fig. 6b). At a relatively low rate of $0.04 \mathrm{C}$ its specific capacity achieved $1183.5 \mathrm{mAhg}^{-1}$. When the charge/ discharge rate was raised up to $0.8 \mathrm{C}$ its specific capacity was still kept above $400 \mathrm{mAh}^{-1}$. However, further pushing up the rate led to distorted charge/discharge curves. The plateau at $2.0 \mathrm{~V}$ in the discharge curve (Stage I) reduced down to $1.8 \mathrm{~V}$ whereas the plateau at $2.2 \mathrm{~V}$ in the charge curve (Stage VI) raised up to $2.3 \mathrm{~V}$. Such distortion can be ascribed to the insufficient electrochemical reactions and high internal resistance, jointly leading to a higher over-potential but lower capacity in the high current density regime. Cycling life and coulombic efficiency are two critical factors for evaluating the practical applications of a battery. the first discharge process at $0.2 \mathrm{C}$ delivered a high capacity of $1260.3 \mathrm{mAh} \mathrm{g}^{-1}$. Unlike the Li-ABP/S battery, the assembled Li-ABP/Ni/graphene/S battery did not show abrupt capacity decay in the second cycle, suggesting better capacity retention (Fig. 6c). The superior capacity retention is ascribed to the synergetic effects of $\mathrm{Ni}$ nanoparticles, graphene, and nanopores in cellulose architecture. In the Li-S battery, the stable $\mathrm{S}_{3}{ }^{\bullet-}$ radical anions play a key role because they are very active and can transfer into the electrolyte [53-56]. Other high order polysulfides $\left(\mathrm{S}_{8}{ }^{2-}, \mathrm{S}_{6}{ }^{2-}\right.$, and $\left.\mathrm{S}_{4}{ }^{2-}\right)$ are either passive phases or semisolids [53], which can easily accumulate on the surface of the cathode, blocking the pathway between the electrode, active material, and electrolyte. The micro/nanopores in $\mathrm{ABP} / \mathrm{Ni} /$ graphene/S cathode were able to encapsulate and immobilize sulfur chains [57,58], ensuring the local chemical environment suitable for more stable $\mathrm{S}_{3}{ }^{\bullet-}$ radical anions [55] as well as avoiding the shuttle effect. Encouragingly, the Li-ABP/ $\mathrm{Ni} / g r a p h e n e / S$ battery exhibited eminent cyclic performance with a recovery of capacity of $832.4 \mathrm{mAh} \mathrm{g}^{-1}$ at $0.2 \mathrm{C}$ after 200 cycles. With the exception of the first few cycles, the ABP/Ni/S-based Li-S battery exhibited excellent coulombic efficiency of almost 100\% even after 200 cycles (Fig. 6d), indicating outstanding coulombic efficiency.

EIS measurements were also carried out to further investigate the electrochemical performance of the assembled $\mathrm{Li}-\mathrm{ABP} / \mathrm{Ni} /$ graphene/S battery. As shown in Fig. 6e, at the early stage of cycling (10th cycle), two semicircles appeared in the high frequency regime. The first one at the relatively higher frequency resulted from the deposition of a passive film on the surface of electrodes, the other one at the intermediate frequency arose from the

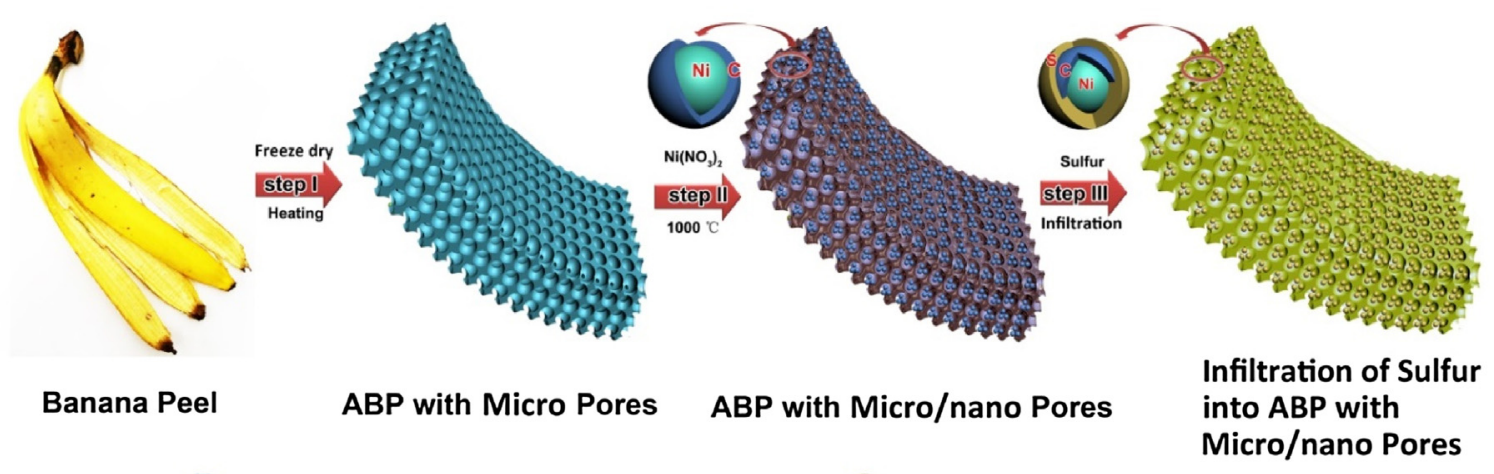

Core/Shell Ni-Multilayered Graphene

Core/Shell Ni-Multilayered Graphene with Sulfur

Fig. 5. Schematic diagram of the detailed processes to convert a banana peel into the ABP/Ni/graphene/S composite. 

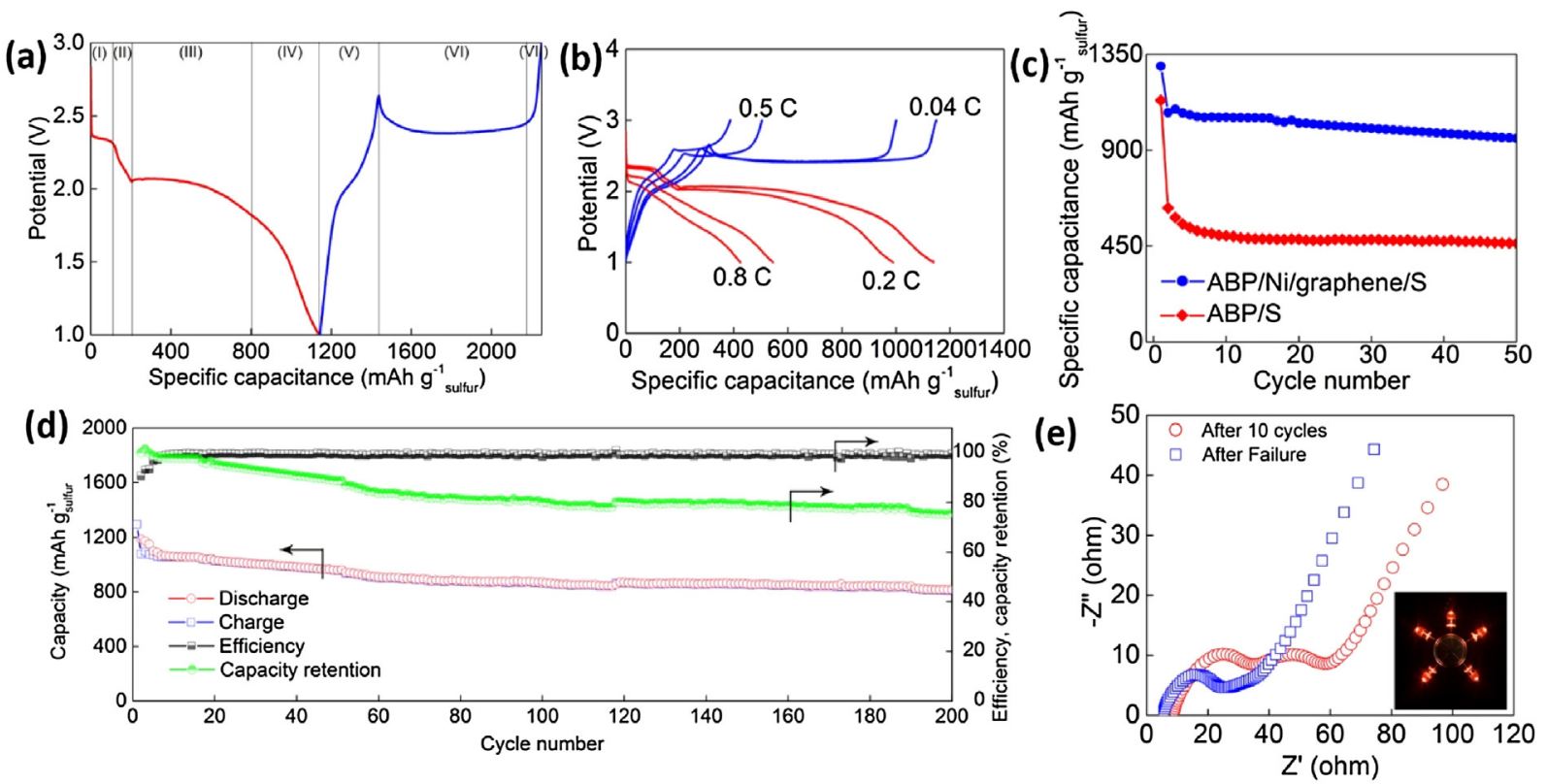

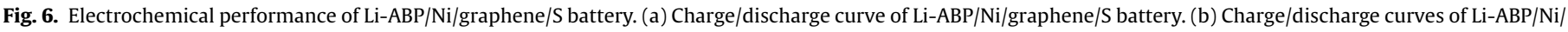

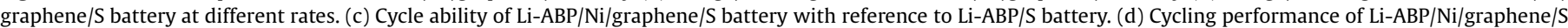

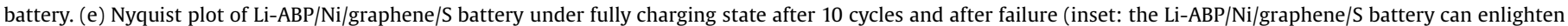
multiple LEDs).

migration of lithium ions through the solid-electrolyte-interphase (SEI) film. The straight line in the low frequency regime was the result of the Li ion diffusion [59]. The intercept of $x$ axis was used to find out the charge transfer resistance, which is closely related to the resistance of interfaces. After failure, the second semicircle disappeared, indicating the broken of SEI film (Fig. 6e) [60]. It is highly possible that large Li dendrites penetrated the SEI. The fracture of the SEI film in turn accelerated the growth of $\mathrm{Li}$ dendrites, resulting in the failure of the battery. The reduced charge transfer resistance and the semicircle at the high frequency regime can be attributed to the rearrangement of insulate sulfur to more electroactive locations and the closer contact between the cathode, separator, and anode as cycling preceded. This bananapeel derived battery is able to enlighten multiple LEDs (see the inset in Fig. 6e). It is noteworthy that the hierarchically porous architecture contributed remarkably to the exceptional electrochemical performance of the Li-ABP/Ni/graphene/S battery. The porous foam-like structure accommodated the volume change during the transformation between sulfur and polysulfides, suppressed the formation of passive films which might impede the electrochemical reactions, mitigated dissolution of polysulfides via trapping and encapsulating multi-atom sulfur chains, and shortened the pathway of ion transfer. Moreover, the highly conductive $\mathrm{Ni} /$ graphene core/shell nanoparticles further facilitated ion transport and electron transfer, while the graphene shell blocked the possible reactions between nickel and sulfur, reducing internal resistance and enhance coulombic efficiency. Considering economic and social benefits of recycling banana peels, such low cost biomass-based activated porous carbon holds an unprecedented promise for energy storage application.

\section{Conclusions}

In summary, banana peels have been successfully converted into hierarchically porous activated carbon scaffolds for energy storage applications. Urchin-like $\mathrm{NiCo}_{2} \mathrm{O}_{4}$ nanowires were uniformly anchored on the surface of $A B P$ through a mild hydrothermal process. $\mathrm{ABP}$ (as the negative electrode) and $\mathrm{NiCo}_{2} \mathrm{O}_{4} / \mathrm{ABP}$ (as the positive electrode) were assembled into a high performance asymmetric supercapacitor. Such banana-peel derived asymmetric supercapacitor exhibited eminent specific capacitance, high power density and competitive cycling robustness. Annealing $\mathrm{Ni}\left(\mathrm{NO}_{3}\right)_{2}$ treated $\mathrm{ABP}$ created nanopores and graphene wrapped Ni nanoparticles simultaneously on the cell walls of ABP. The hierarchically porous $\mathrm{ABP} / \mathrm{Ni} /$ graphene architecture accommodated the volume change during the charge/discharge cycling, suppressed the formation of passive layer, mitigated dissolution of polysulfides via trapping and encapsulating multi-atom sulfur chains, and shortened the pathway of ion transfer. Moreover, the highly conductive $\mathrm{Ni}$ nanoparticles and graphene further enhanced electron transfer, ensuring low internal resistance and high coulombic efficiency. The banana-peel derived supercapacitors and batteries present a new promise for the design and fabrication of high performance energy storage devices while reducing material waste.

\section{Acknowledgements}

Financial support for this study was provided by the U.S. National Science Foundation (CMMI-1418696 and CMMI-1358673) and the i6 Virginia Innovation Partnership. The authors thank the staff members at the University of Virginia NMCF for electron microscopy technical support.

\section{Appendix A. Supplementary data}

Supplementary data associated with this article can be found, in the online version, at http://dx.doi.org/10.1016/j. electacta.2016.11.099.

\section{References}

[1] H.K. Liu, An overview-functional nanomaterials for lithium rechargeable batteries, supercapacitors, hydrogen storage, and fuel cells, Mater. Res. Bull. 48 (12) (2013) 4968-4973.

[2] P. Simon, Y. Gogotsi, B. Dunn, Where do batteries end and supercapacitors begin? Science 343 (2014) 1210-1211. 
[3] J.B. Goodenough, Y. Kim, Challenges for rechargeable batteries, J. Power Sources 196 (16) (2011) 6688-6694.

[4] C. Liu, F. Li, L.-P. Ma, H.-M. Cheng, Advanced materials for energy storage, Adv. Mater. 22 (8) (2010) E28-E62.

[5] C. Yang, H. Wei, L. Guan, J. Guo, Y. Wang, X. Yan, X. Zhang, S. Wei, Z. Guo, Polymer nanocomposites for energy storage energy saving, and anticorrosion, J. Mater. Chem. A 3 (2015) 14929-14941.

[6] H. Chen, T. Liu, J. Ren, H. He, Y. Cao, N. Wang, Z. Guo, Synergistic carbon nanotube aerogel - Pt nanocomposites toward enhanced energy conversion in dye-sensitized solar cells, J. Mater. Chem. A 4 (2016) 3238-3244.

[7] E. Frackowiak, F. Béguin, Carbon materials for the electrochemical storage of energy in capacitors, Carbon 39 (6) (2001) 937-950.

[8] D.-W. Wang, F. Li, M. Liu, G.Q. Lu, H.-M. Cheng, 3D aperiodic hierarchical porous graphitic carbon material for high-rate electrochemical capacitive energy storage, Angew. Chem. Int. Ed. 120 (2) (2008) 379-382.

[9] L. Ji, M. Rao, S. Aloni, L. Wang, E.J. Cairns, Y. Zhang, Porous carbon nanofibersulfur composite electrodes for lithium/sulfur cells, Energy Environ. Sci. 4 (2011) 5053-5059.

[10] A.S. Aricò, P. Bruce, B. Scrosati, J.-M. Tarascon, W. van Schalkwijk, Nanostructured materials for advanced energy conversion and storage devices, Nat. Mater. 4 (2005) 366-377.

[11] Food and agriculture organization of the United Nations. http://faostat3.fao. org/faostat-gateway/go/to/search/banana/E.

[12] N. Bardiya, D. Somayaji, S. Khanna, Biomethanation of banana peel and pineapple waste, Bioresour. Technol. 58 (1) (1996) 73-76.

[13] A. Bhatnagar, M. Sillanpää, Utilization of agro-industrial and municipal waste materials as potential adsorbents for water treatment-A review, Chem. Eng. J $157(2-3)$ (2010) 277-296.

[14] G. Annadural, R.S. Juang, D.J. Lee, Adsorption of heavy metals from water using banana and orange peels, Water Sci. Technol. 47 (1) (2003) 185-190.

[15] V. Subramanian, C. Lou, A.M. Stephan, K.S. Nahm, B. Thomas, J. Wei, Supercapacitors from activated carbon derived from banana fibers, J. Phys. Chem. C 111 (20) (2007) 7527-7531.

[16] Y. Lv, L. Gan, M. Liu, W. Xiong, Z. Xu, D. Zhu, D.S. Wright, A self-template synthesis of hierarchical porous carbon foams based on banana peel for supercapacitor electrodes, J. Power Sources 209 (1) (2012) 152-157.

[17] L. Wang, X. Li, J. Ma, Q. Wu, X. Duan, Non-activated, N, S-co-doped biochar derived from banana with superior capacitive properties, Sust. Energy 2 (2) (2014) 39-43.

[18] E.M. Lotfabad, J. Ding, K. Cui, A. Kohandehghan, W.P. Kalisvaart, M. Hazelton, D. Mitlin, High-density sodium and lithium ion battery snodes from banana peels, ACS Nano 8 (7) (2014) 7115-7129.

[19] B. Liu, L. Zhang, P. Qi, M. Zhu, G. Wang, Y. Ma, X. Guo, H. Chen, B. Zhang, Z. Zhao, B. Dai, F. Yu, Nitrogen-doped banana peel-derived porous carbon foam as binder-free electrode for supercapacitors, Nanomaterials 6 (2016) 18.

[20] M. Zhi, C. Xiang, J. Li, M. Li, N. Wu, Nanostructured carbon-metal oxide composite electrodes for supercapacitors: A review, Nanoscale 5 (2013) 72-88.

[21] G. Wang, L. Zhang, J. Zhang, A review of electrode materials for electrochemical supercapacitors, Chem. Soc. Rev. 41 (2012) 797-828.

[22] H. Wei, X. Yan, S. Wu, Z. Luo, S. Wei, Z. Guo, Electropolymerized polyaniline stabilized tungsten oxide nanocomposite films: electrochromic behavior and electrochemical energy storage, J. Phys. Chem. C 116 (47) (2012) 25052-25064.

[23] H. Wei, C. He, J. Liu, H. Gu, Y. Wang, X. Yan, J. Guo, D. Ding, N.Z. Shen, X. Wang, S. Wei, Z. Guo, Electropolymerized polypyrrole nanocomposites with cobalt oxide coated on carbon paper for electrochemical energy storage, Polymer 67 ( 12) (2015) 192-199.

[24] S. Guo, J. Liu, S. Qiu, W. Liu, Y. Wang, N. Wu, J. Guo, Z. Guo, Porous ternary $\mathrm{TiO}_{2}$ $\mathrm{MnTiO}_{3} @ \mathrm{C}$ hybrid microspheres as anode materials with enhanced electrochemical performances, J. Mater. Chem. A 3 (2015) 23895-23904.

[25] S. Guo, J. Liua, S. Qiu, Y. Wang, X. Yan, N. Wu, S. Wang, Z. Guo, Enhancing electrochemical performances of $\mathrm{TiO}_{2}$ porous microspheres through hybridizing with $\mathrm{FeTiO}_{3}$ and nanocarbon, Electrochim. Acta 190 (1) (2016) 556-565.

[26] H. Wang, Q. Gao, L. Jiang, Facile approach to prepare nickel cobaltite nanowire materials for supercapacitors, Small 7 (17) (2011) 2454-2459.

[27] T.-Y. Wei, C.-H. Chen, H.-C. Chien, S.-Y. Lu, C.-C. Hu, A cost-effective supercapacitor material of ultrahigh specific capacitances: spinel nickel cobaltite aerogels from an epoxide-driven sol-gel process, Adv. Mater. 22 (3) (2010) 347-351.

[28] H.-C. Chien, W.-Y. Cheng, Y.-H. Wang, S.-Y. Lu, Ultrahigh specific capacitances for supercapacitors achieved by nickel cobaltite/carbon aerogel composites, Adv. Funct. Mater. 22 (23) (2012) 5038-5043.

[29] J.B. Goodenough, Y. Kim, Challenges for rechargeable Li batteries, Chem. Mater. 22 (3) (2010) 587-603.

[30] P.G. Bruce, B. Scrosati, J.-M. Tarascon, Nanomaterials for rechargeable lithium batteries, Angew. Chem. Int. Ed. 47 (16) (2008) 2930-2946.

[31] P.G. Bruce, S.A. Freunberger, L.J. Hardwick, J.-M. Tarascon, $\mathrm{Li}_{-} \mathrm{O}_{2}$ and Li-S batteries with high energy storage, Nat. Mater. 11 (2012) 19-29.

[32] S.-E. Cheon, K.-S. Ko, J.-H. Cho, S.-W. Kim, E.-Y. Chin, H.-T. Kim, Rechargeable lithium sulfur battery I. Structural change of sulfur cathode during discharge and charge, J. Electrochem. Soc. 150 (6) (2003) A796-A799.
[33] S.-E. Cheon, K.-S. Ko, J.-H. Cho, S.-W. Kim, E.-Y. Chin, H.-T. Kim, Rechargeable lithium sulfur battery II. Rate capability and cycle characteristics, J. Electrochem. Soc. 150 (6) (2003) A800-A805.

[34] M.-K. Song, E.J. Cairns, Y. Zhang, Lithium/sulfur batteries with high specific energy: old challenges and new opportunities, Nanoscale 5 (2013) 2186-2204.

[35] X. Ji, K.T. Lee, L.F. Nazar, A highly ordered nanostructured carbon-sulphur cathode for lithium-sulphur batteries, Nat. Mater. 8 (2009) 500-506.

[36] M.-K. Song, Y. Zhang, E.J. Cairns, A long-life, high-rate lithium/sulfur cell: multifaceted approach to enhancing cell performance, Nano Lett. 13 (12) (2013) 5891-5899.

[37] S. Moser, T. Müller, A. Holzinger, C. Lütz, S. Jockusch, N.J. Turro, B. Kräutler, Fluorescent chlorophyll catabolites in bananas light up blue halos of cell death, Proc. Natl. Acad. Sci. U. S. A. 106 (37) (2009) 15538-15543.

[38] S. Brunauer, P.H. Emmett, E. Teller, Adsorption of gases in multimolecular layers, J. Am. Chem. Soc. 60 (2) (1938) 309-319.

[39] Z. Gao, N. Song, Y. Zhang, X. Li, Cotton textile enabled, all-solid-state flexible supercapacitors, RSC Adv. 5 (2015) 15438-15447.

[40] L. Bao, X. Li, Towards textile energy storage from cotton T-shirts, Adv. Mater. 24 (24) (2012) 3246-3252.

[41] Z. Gao, W. Yang, J. Wang, N. Song, X. Li, Flexible all-solid-state hierarchical $\mathrm{NiCO}_{2} \mathrm{O}_{4}$ /porous graphene paper asymmetric supercapacitors with an exceptional combination of electrochemical properties, Nano Energy 13 (2015) 306-317.

[42] L. Demarconnay, E. Raymundo-Piñero, F. Béguin, Adjustment of electrodes potential window in an asymmetric carbon/ $\mathrm{MnO}_{2}$ supercapacitor, J. Power Sources 196 (1) (2011) 580-586.

[43] H. Wang, Y. Yang, Y. Liang, J.T. Robinson, Y. Li, A. Jackson, Y. Cui, H. Dai, Graphene-wrapped sulfur particles as a rechargeable lithium-sulfur battery cathode material with high capacity and cycling stability, Nano Lett. 11 (7) (2011) 2644-2647.

[44] X. Zhang, W. Wang, A. Wang, Y. Huang, K. Yuan, Z. Yu, J. Qiu, Y. Yang, Improved cycle stability and high security of Li-B alloy anode for lithium/sulfur battery, J. Mater. Chem. A 2 (2014) 11660-11665.

[45] D.S. Jung, T.H. Hwang, J.H. Lee, H.Y. Koo, R.A. Shakoor, R. Kahraman, Y.N. Jo, M.S Park, J.W. Choi, Hierarchical porous carbon by ultrasonic spray pyrolysis yields stable cycling in lithium-sulfur battery, Nano Lett. 14 (8) (2014) 4418-4425.

[46] G. Zhou, S. Pei, L. Li, D.-W. Wang, S. Wang, K. Huang, L.-C. Yin, F. Li, H.-M. Cheng, A graphene-pure-sulfur sandwich structure for ultrafast, long-life lithiumsulfur batteries, Adv. Mater. 26 (4) (2014) 625-631.

[47] W. Brockner, C. Ehrhardt, M. Gjikaj, Thermal decomposition of nickel nitrate hexahydrate, $\mathrm{Ni}\left(\mathrm{NO}_{3}\right)_{2} \cdot 6 \mathrm{H}_{2} \mathrm{O}$, in comparison to $\mathrm{Co}\left(\mathrm{NO}_{3}\right)_{2} \cdot 6 \mathrm{H}_{2} \mathrm{O}$ and $\mathrm{Ca}$ $\left(\mathrm{NO}_{3}\right)_{2} \cdot 4 \mathrm{H}_{2} \mathrm{O}$, Thermochim. Acta 456 (1) (2007) 64-68.

[48] K.S. Kim, Y. Zhao, H. Jang, S.Y. Lee, J.M. Kim, K.S. Kim, J.-H. Ahn, P. Kim, J.-Y. Choi, B.H. Hong, Large-scale pattern growth of graphene films for stretchable transparent electrodes, Nature 457 (2009) 706-710.

[49] A.N. Obraztsov, E.A. Obraztsova, A.V. Tyurnina, A.A. Zolotukhin, Chemical vapor deposition of thin graphite films of nanometer thickness, Carbon 45 (10) (2007) 2017-2021.

[50] M. Liu, X. Ma, L. Gan, Z. Xu, D. Zhu, L. Chen, A facile synthesis of a nove mesoporous Ge@C sphere anode with stable and high capacity for lithium ion batteries, J. Mater. Chem. A 2 (2014) 17107-17114.

[51] M. Liu, J. Qian, Y. Zhao, D. Zhu, L. Gan, L. Chen, Core-shell ultramicroporous@microporous carbon nanospheres as advanced supercapacitor electrodes, J. Mater. Chem. A 3 (2015) 11517-11526.

[52] W. Lu, M. Liu, L. Miao, D. Zhua, X. Wang, H. Duan, Z. Wang, L. Li, Z. Xu, L. Gan, L Chen, Nitrogen-containing ultramicroporous carbon nanospheres for high performance supercapacitor electrodes, Electrochim. Acta 205 (1) (2016) 132 141.

[53] Q. Wang, J. Zheng, E. Walter, H. Pan, D. Lv, P. Zuo, H. Chen, Z.D. Deng, B.Y. Liaw, X. Yu, X. Yang, J.-G. Zhang, J. Liu, J. Xiao, Direct observation of sulfur radicals as reaction media in lithium sulfur batteries, J. Electrochem. Soc. 162 (3) (2015) A474-A478.

[54] Z. Gao, N. Song, Y. Zhang, X. Li, Cotton-textile-enabled, rlexible lithium-ion batteries with enhanced capacity and extended lifespan, Nano Lett. 15 (12) (2015) 8194-8203.

[55] M.A. Lowe, J. Gao, H.D. Abruña, Mechanistic insights into operational lithiumsulfur batteries by in situ X-ray diffraction and absorption apectroscopy, RSC Adv. 4 (2014) 18347-18353.

[56] M. Wild, L. O’Neill, T. Zhang, R. Purkayastha, G. Minton, M. Marinescu, G.J. Offer Lithium Sulfur Batteries, A Mechanistic Review, Energy Environ. Sci. 8 (2015 3477-3494.

[57] S. Zhang, K. Ueno, K. Dokko, M. Watanabe, Recent advances in electrolytes for lithium-sulfur batteries, Adv. Energy Mater. 5 (16) (2015) 1500117.

[58] Y.V. Mikhaylik, J.R. Akridge, Polysulfide Shuttle Study in the Li/S Nattery System, J. Electrochem. Soc. 151 (11) (2004) A1969-A1976.

[59] N.J. Dudney, Addition of a thin-film inorganic solid electrolyte (lipon) as a protective film in lithium batteries with a liquid electrolyte, J. Power Sources 89 (2) (2000) 176-179.

[60] X. Liang, Z. Wen, Y. Liu, M. Wu, J. Jin, H. Zhang, X. Wu, Improved cycling performances of lithium sulfur batteries with $\mathrm{LiNO}_{3}$-modified electrolyte, J. Power Sources 196 (22) (2011) 9839-9843. 